\title{
18. Remarks on the Genus Comalia Wells with the Description of a New Species from the Jurassic of Japan.
}

\author{
By Hisakatsu YABE and Toshio Sugryama. \\ (Comm. by H. YABE, M.1.A., Feb. 13, 1933.)
}

Comatia is a genus of hexacorals recently established by J.W. Wells $^{1)}$ on Comalia fasciculata Wells from the Lower Cretaceous of Central Texas, North America. It bears a great resemblance to certain forms of the Tabulata on one side and to some hexacorals on the other. The generic diagnosis given by him is as follows:

"The corallum is colonial, massive, forming more or less columnar masses covered laterally by a wrinkled epitheca. The corallites are slender, tall, prismatic, polygonal in outline, or subtriangular, with deep calices opening vertically. The imperforate corallite walls are separate, sometimes united by thin exotheca, occasionally fused near the calices. The septa are rudimentary but relatively well developed for this group of corals, forming three ridges on the corallite wall as in the Palaeozoic genus Alveolites. One of the septa is usually better developed than the others and extends from the wall nearly to the center of the corallite where it terminates in a swelling or bifurcation. Tabulae are well developed, numerous, confined to the individual corallites, i.e., not extending between the corallites, arching upwards slightly. Increase by gemmation."

According to him, Comalia somewhat resembles Alveolites in the habit of septa and Chaetetes, Diplochaetetes and Blastochaetetes in the general structure of the corallum. He distinguished it from latter three by the possession of three septa, and more particularly from Chaetetes and Blastochaetetes by separate corallite walls and from Diplochaetetes by a different mode of increase of corallites and more abundant tabulae.

Our Torinosu limestone of the Jurassic contains a rich coral fauna, which consists essentially of hexacorals, hydrozoan and tabulate corals. ${ }^{2>}$ Among the corals there is a peculiar form closely simulating Favosites, yet having affinity for hexacorals in certain features; it is fairly common and we have many specimens of it in the collection of our Institute of Geology and Palaeontology; some of the specimens are fragments of large massive stocks some $40-50 \mathrm{~cm}$. in diameter. This coral, known

1) J.W. Wells: Corals of the Trinity Group of the Comanchean of Central Texas. Jour. Palaeont., Vol. 6 No. 3, (1932), 255.

2) H. Yabe: Cretaceous Stratigraphy of the Japanese Islands. Sci. Rep. Tohoku Imp. Univ., Sendai, Ser. II. (Geol.), Vol. 9 No. 1, (1927), 89. 
to us for a long time, but left underscribed until now, exhibits strong similarity to Comalia fasciculata cited above in every respect, and their generic identity is undeniable, though certain features of the corallum seem to require an interpretation different from that given by Wells. Further, the true affinity of Comalia is, we believe, to the Seriatoporidae (particularly to Pocillopora) and not the Chaetetidae.

\section{Comalia asiatica Yabe and Sugiyama, sp. nov.}

Figs. 1-3.

Corallum forming massive stocks of a considerable size; composed of numerous long and narrow, erect, prismatic corallites. Corallites 1.5-1 mm. broad, contiguous, rounded pentagonal or hexagonal in crosssection. Walls imperforate, $0.1-0.3 \mathrm{~mm}$. broad on the average. Septa in two different kinds ; rudimentary septa 12 or more in number, being little more than raised longitudinal striae of corallite walls. Longer septa 1-3, thin lamellar, flexuous and not persistent, vanishing locally ; one of them almost always extending to the center of corallites, where it swells to form a kind of faint columella and is sometimes united with other long septa, then assuming an aspect of bi- or trifurcation of the primary lamella. Tabulae well developed, complete, usually horizontal and occasionally convex upwards; $0.5-1 \mathrm{~mm}$. apart. Increase by gemmation and also rarely by fission?

Remarks: This species is easily distinguished from the genotype of Comalia, Comalia fasciculata, by having corallites rounded pentagonal or hexagonal in transverse section and septa differently disposed; in the North American species, corallites are less equidimentional in transverse outline, being subtrigonal or semicircular. Furthermore septa are usually 3 in number, and Wells did not make mention of the occurrence of rudimentary ones in his species. These differences have only specific and no generic value.

When we examine thin sections of the Japanese fossil under the microscope, the corallite walls show a median dark line and each corallite appears as if being provided with its own wall. Sometimes the preservation is reversed and the walls then show a broad lucid median part lined on both sides by a dark line. In these respects as well as in detailed microstructures the corallite walls of our fossil are hardly distinguishable from those of living Pocillopora $;{ }^{1)}$ in the latter genus the

1) P.M. Duncan: A Revision of the Families and Genera of the Sclerodermic Zoantharia, Ed. \& H., or Mardeporaria. Jour. Linn. Soc. London, Zool. 18 (1884), 47. 
corallites are, as stated by Duncan, usually crowded terminally, angular and closely united by their walls, while they are elsewhere more or less separated by compact coenenchym, which is sharply spinulose or granular on the surface.

Pocillopora is, in fact, the only genus of corals which has numerous features in common with Comalia; besides the microstructure of corallite walls referred to above, both agree with each other in having crowded corallites usually polygonal in transverse outline, surrounded by compact walls, either almost in direct contact or separated by a thin compact coenenchym, and traversed by rather distant platy tabulae. In Pocillopora, however, the columella, though discontinuous, is more definite and stouter than in Comalia; septa are usually rudimentary, but sometimes two opposite ones are elongated and united at the columella to form a continuous lamella dividing the deep calicinal fossa into two symmetrical halves. The unforced conclusion arrived at from the above comparison of the two genera Pocillopora and Comalia is that they are intimately related and may safely be brought into one and the same family Seriatoporidae.

Localities and geological horizon: Okuminodani near Ryoseki, Kureda-mura, Nagaoka-gun, province of Tosa (Reg. No. 44404) ; Konpirayama, Tokanô-mura (Reg. No. 44405 and 44403), and Arinoki near Sakawa-machi (Holotype: Reg. No. 43475), both in Takaoka-gun, province of Tosa. Torinosu limestone; Upper Jurassic. 


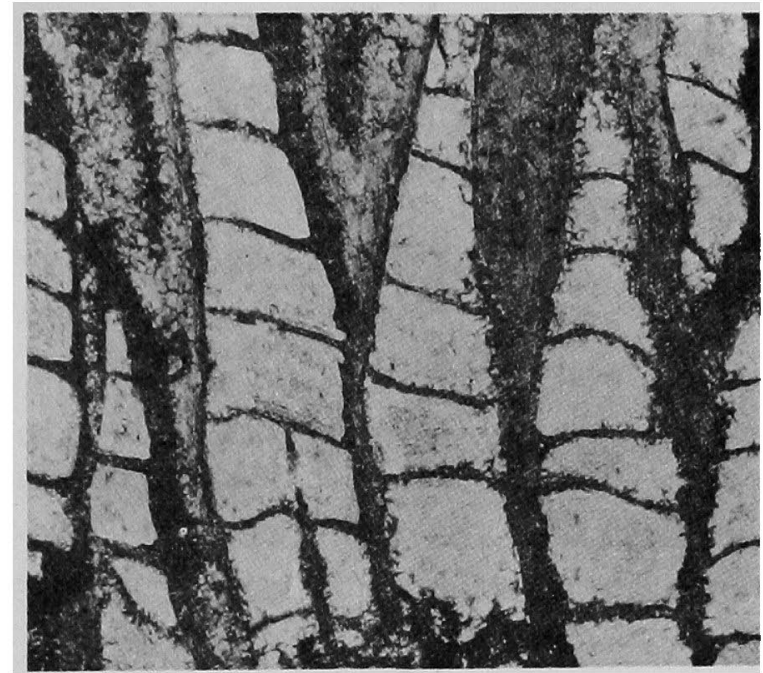

3
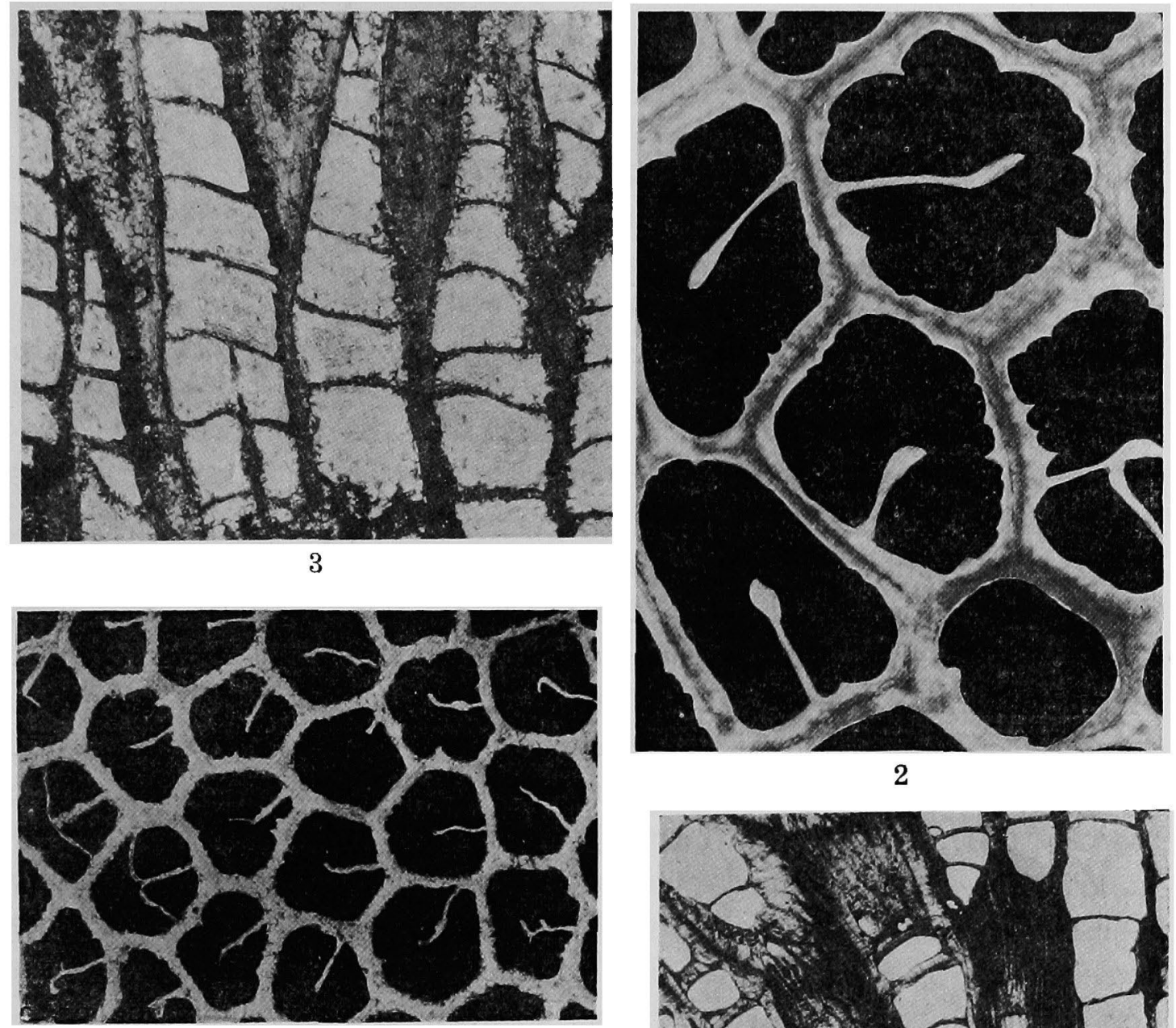

1

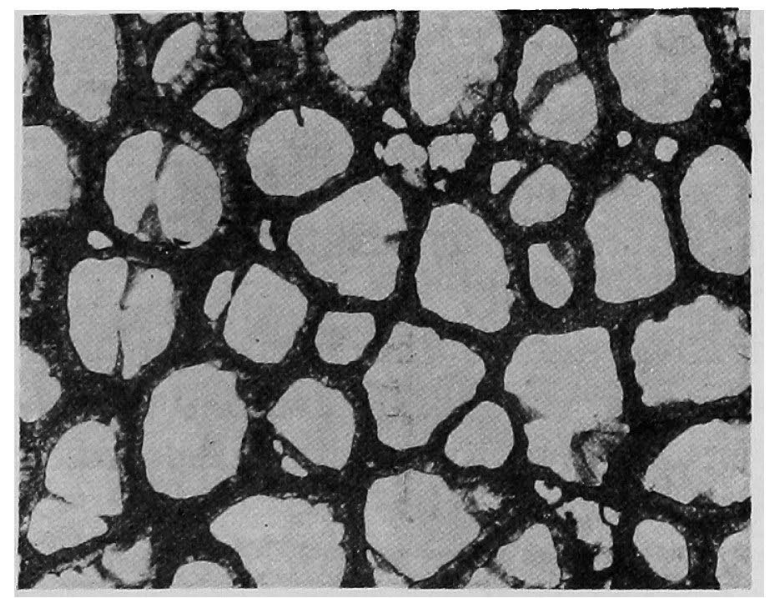

4

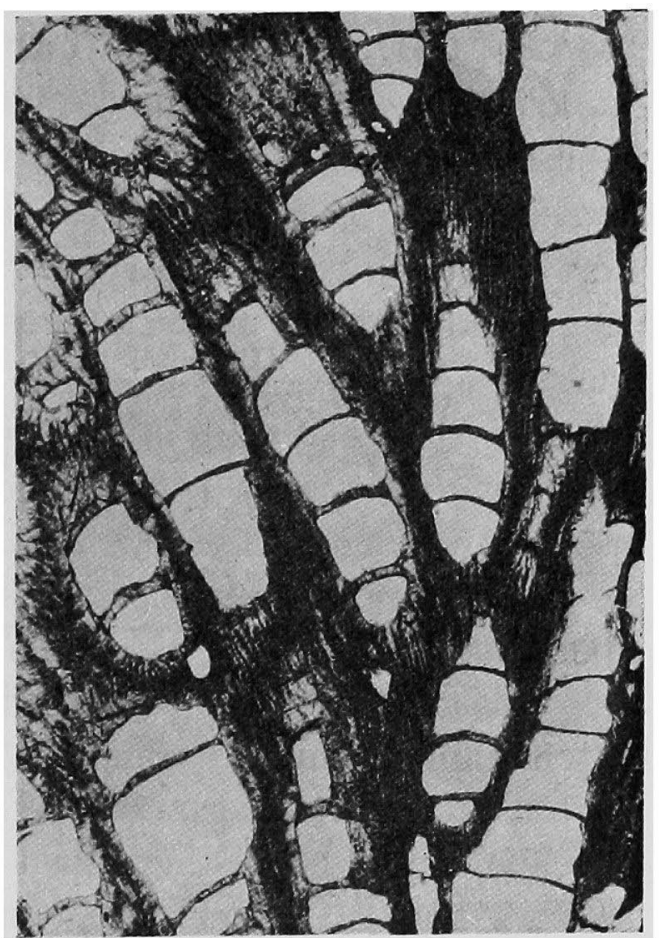

5

Figs. 1-3. Comalia asiatica sp. nov. from the Upper Jurassic Torinosu limestone of Arinoki near Sakawa-machi, Takaoka-gun, province of Tosa.

Corallites in transverse $(1, \times 10 ; 2, \times 20)$, and longitudinal section $(3, \times 10)$.

Figs. 4, 5. Pocillopora cfr. maeandrina Dana var. nobilis Verrill from Chichi-jima, Ogasawara Islands; recent.

Corallites in transverse $(4, \times 10)$ and longitudinal section $(5, \times 10)$. 